\title{
Swiss teenagers, AIDS and sexually transmitted diseases: presentation and evaluation of a preventive exhibition
}

\author{
P.-A.Michaud ${ }^{1}$ and D.Hausser ${ }^{2}$
}

Abstract

As part of a larger school-based health program for Swiss apprentices and students, an AIDS and sexually transmitted disease (STD) prevention exhibition was offered to 7000 boys and girls aged 15-19. Its objectives were: (1) to reinforce their knowledge of STD and AIDS transmission and prevention, and (2) to modify their attitudes and behavior regarding (a) the decision whether, when and how to have sex and (b) the use of condoms. The exhibition consisted of six posters, reviewed by specially-trained teachers and nurses. Condoms were presented in an amusing way and were freely available. A case control follow-up survey was carried out 12 weeks later in two random samples: 798 subjects from an experimental school and 600 subjects from a control school completed an anonymous multiple-choice questionnaire. Of the respondents, $69 \%$ were sexually active, and among this group, $76 \%$ of the boys and $59 \%$ of the girls had used a condom at least once but only $15 \%$ used them regularly. As regards knowledge, both groups reached high levels (75-97\% of right answers); the group exposed to the exhibition scored higher for only two items $(P<0.05)$. Significantly more teenagers in the experimental group said they had handled condoms or had condoms with them 'just in case ...'. This evaluation shows that an AIDS and STD prevention exhibition for teenagers may be both feasible and effective. However, future intervention programs should include practical interpersonal counseling

\footnotetext{
'Service de la Santé Publique et de ba Planification Sanitaire and ${ }^{2}$ Institut Universitaire de Médecine Sociale et Préventive, Lausanne, Vaud, Switzertand
}

on topics such as mutual trust, contraception issues, and the purchase and use of condoms.

\section{Introduction}

Switzerland, a confederation of 23 cantons, currently has the highest proportion of AIDS patients in Europe, with a rate that was around 174 per million people in December 1989 (Office Fédéral de la Santé Publique). This serious situation explains why the Swiss Federal Office for Public Health planned a national campaign against AIDS, which was launched in February 1987, and which is aimed at the entire population. This campaign, called 'STOP AIDS', is still going on and consists of TV advertisements and programs on AIDS, street posters and pamphlets directed at young people, homosexuals and pregnant women, and action directed at so-called high-risk groups. The use of condoms for sexual relationshps with multiple or casual partners, the non-sharing of injection equipment for drug users, as well as the notion of fidelity between sexual partners, are all heavily emphasized. This extensive campaign has been subjected to an evaluation (Hausser et al., 1988, 1989, 1990).

Even if all adolescents cannot be considered at risk, they represent an important target group for an AIDS prevention program, since they are in a process of discovering their sexuality and often have more than one partner-some of whom may exhibit high-risk behavior. At the present time, one of the most efficient ways to prevent the spread of AIDS among young people is to promote the use of condoms as widely as possible. This type of primary prevention also constitutes a good measure against sexually transmitted disease (STD) (Martin and Michaud, 1988). The use of the HIV test should be dis- 
couraged, as it can wrongly reinforce adolescents' feeling of invulnerability (Martin and Michaud, 1988; Office Fédéral de la Santé Publique, 1988).

The present paper focuses on the presentation of an AIDS and STD prevention exhibition developed in January 1987 in a large vocational school of about 7000 apprentices aged 16-19 in the canton of Vaud, Switzerland. It also gives the main results of a survey which was conducted 3 months later in this center and in another similar school.

The exhibition was developed within the general context of a 6 year old school health project, called the 'Youth and Health Program' (Michaud and Martin, 1984) which is mainly promoted by public health nurses working in close coordination with physicians and teachers. It offers, in the general field of health monitoring and promotion, individual screening based on a comprehensive health interview, emergency and non-emergency individual counseling and care and, finally, health education activities which take into account the needs and wishes of the pupils themselves. As the same nurses are responsible for all the activities, close coordination between these three aspects of the program can be guaranteed. The project described in this paper is an example of this concept of prevention.

\section{The exhibition}

The objectives of the AIDS-STD exhibition were as follows (Michaud et al., 1987; Martin and Michaud, 1988):

(1) To improve young people's knowledge of the transmission and prevention of AIDS and STDs, focusing on the practical means which prevent the transmission of the virus and on the situations that carry no risk of infection.

(2) To modify teenagers' attitudes and behavior towards contraception in terms of fostering discussion with their partners and choice of condoms.

(3) To help young people take personal and responsible decisions about their sex life: this objective implies the inclusion of psycho-social and ethical issues in the discussion.
(4) To give apprentices personally concerned about AIDS and STDs an opportunity to discuss their problems with one of the public health nurses working in the school. If necessary, they are given addresses of where to find medical and/or psychological help.

The preparation of the exhibition was a 3 month long process that included the collaboration of certain pupils and teachers. It was decided that it would deal above all with the everyday life aspects of STD and HIV transmission and prevention and not with theoretical matters. The problems would be presented in a comprehensive and positive way. The language would be simple and understandable but not titillating.

The project included a six-panel exhibition, dealing with sex life, AIDS and STD transmission, STD symptoms, the use of condoms and, finally, the way to behave with HIV carriers and AIDS patients. The exhibition was presented and constantly manned by nurses, teachers or other specially-trained staff. Each class of around 15 pupils spent $20-30$ minutes in the exhibition. The discussions were very encouraging in most instances. Condoms were exhibited in various ways: sketched, inflated and knitted; humour was part of the exhibition! Condoms were also available: around 30000 of them were distributed.

Individuals who had more questions or who needed counseling were invited to go to the nurse's office, where a member of staff was always on hand.

The exhibition was $75 \%$ funded by the Swiss Federal Office of Public Health, and the Cantonal Public Health Service provided the remainder. It cost, together with the evaluation process, US\$15000.

\section{Methodology of the survey}

The objectives of the evaluation were: (1) to obtain base-line data on the knowledge apprentices had of STDs and AIDS, as well as their attitudes towards contraception (i.e. condom use) and their sexual behavior, and (2) to measure the impact of the exhibition.

We chose a quasi-experimental design using a post- 
test with a control group. Three months after the exhibition, two samples of classes were selected, one from the experimental school and another from a control school which was smaller than the experimental school but similar in other respects. The apprentices were asked to complete an anonymous two-page multiple-choice questionnaire dealing with knowledge of AIDS and STDs, attitudes towards contraception, sexual behavior, and demographic information such as age, sex, type of job and place of residence. The instrument was not internally validated but was tested and further modified before extensive use. No one refused to fill in the questionnaire. Answer rates to different questions ranged from $70 \%$ to over $90 \%$ (mostly above $90 \%$ ).

We did not seek to distinguish between heterosexual and homosexual behavior: this topic was, in our context, too sensitive to be included in such a brief questionnaire.

The results were processed with SPSS for crosstabulations and classical regression analysis.

\section{Results}

\section{Study sample}

The sample covered by the survey (Table I) consisted of 1398 French-speaking 16-20 year old apprentices, of whom $71 \%$ was boys. There was no significant difference between the experimental and the control group in terms of age, but boys, sexually active individuals and adolescents who lived in towns and cities (more than 5000 inhabitants), were slightly over-represented in the experimental group. The distribution of trades (not seen in the figure) was, overall, the same in both groups.

\section{Knowledge}

Concerning knowledge of AIDS, around $10 \%$ of the respondents felt very well informed, $70 \%$ fairly well informed, 15\% not well informed and 5\% ill informed. There was no statistical difference between either groups, nor between boys and girls.

The percentages of correct answers to different items (Table II) varied between $68 \%$ and $95 \%$, with a slight difference in favor of the experimental group for some items, such as non-transmission of the virus via all types of kissing and the absence of risk of contamination from the hairdresser.

A cumulative index of correct answers was constructed: $40 \%$ of the respondents made no mistakes (out of a total of 11 items), $30 \%$ one or two errors, $20 \%$ three to six errors and $10 \%$ more than six. There was no difference between the experimental and the control groups. Boys and girls, sexually active as well as inactive, had similar levels of knowledge.

\section{Attitudes}

Attitudes towards condom use were not only more difficult to assess but also not easy to interpret: even if young people say they are willing to use condoms, one does not exactly know to what extent they will really do so when having sexual relations. As

\begin{tabular}{lccc}
\hline \multicolumn{3}{c}{ Table I. Srudy sample } & \\
\hline & $\begin{array}{c}\text { Experimental group } \\
N=822 \\
(\text { (\%) }\end{array}$ & $\begin{array}{c}\text { Control group } \\
N=576 \\
(\%)\end{array}$ & $\begin{array}{c}\text { Differences } \\
P \text {-values } \\
\left(x^{2}\right)\end{array}$ \\
\hline Boys & 79 & 68 & 0.001 \\
Girls & 21 & 32 & NS \\
$<17$ years & 40 & 44 & \\
$\geq 17$ years & 60 & 56 & 0.01 \\
Sexually active & 22 & 30 & \\
Sexually inactive & 78 & 70 & 0.001 \\
Urban & 71 & 61 & \\
Rural & 29 & 39 & \\
& & & \\
\hline
\end{tabular}


Table III shows, virtually all respondents (99\%) knew what a condom is and most of them had handled one. Nearly $70 \%$ had discussed the topic of condom use with their partner. Far more boys than girls had purchased condoms or had one on them 'just in case ...'.

Respondents were also asked what they would do if they considered having sex with a partner they did not know well [an 'at risk situation' (Table IV)]. Half of the respondents claimed they would be ready to use a condom-although there must be some doubt whether the youngsters who say they would use condoms readily really would do so when faced with a situation in reality. Perhaps the $15 \%$ who say they would experience difficulty are more realistic! The majority of the rest of the respondents did not feel concerned because they felt they would not face this situation (girls more so than boys, $P<0.005$ ). Again, whereas $50 \%$ considered the use of condoms convenient and safe, one-third had a negative

\begin{tabular}{lcc}
\hline & Tabłe II. Knowledge of transmission of HIV infection & $\begin{array}{c}\text { Differences between } \\
\text { experimental/control schools } \\
(P \text {-values })\end{array}$ \\
\hline Kissing & $\begin{array}{c}\text { Correct } \\
\text { answers } \\
(\$)\end{array}$ & 0.05 \\
Sharing food & 95.6 & 0.1 \\
Going to the hairdresser's & 97.9 & 0.05 \\
Not washing after sexual intercourse & 97.0 & 0.2 \\
Cat scratches/mosquito bites & 75.2 & 0.2 \\
Swimming pool & 94.8 & 0.2 \\
Shaking hands & 97.0 & 0.2 \\
Having sex with a drug addict & 99.5 & 0.7 \\
In public toilets & 97.0 & 0.6 \\
Injecting drugs & 87.0 & 0.9 \\
Sharing everyday life with a homosexual & 94.9 & 0.08 \\
\hline
\end{tabular}

Table III. General attitudes to condoms

\begin{tabular}{lccc}
\hline & $\begin{array}{c}\text { Boys } \\
N=862 \\
(\Phi)\end{array}$ & $\begin{array}{c}\text { Girls } \\
=332 \\
(\%)\end{array}$ & $\begin{array}{c}\text { Differences } \\
(P \text {-values })\end{array}$ \\
\hline Have you ever heard of condoms? & 99.5 & 99.7 & 0.8 \\
Have you ever handled condoms? & 93.9 & 75.8 & 0.0001 \\
Have you discussed condom use with your partner? & 68.9 & 65.1 & 0.1 \\
Have you cver bought condoms? & 57.5 & 16.6 & 0.0001 \\
Do you have condoms with you just in case ...? & 41.3 & 10.2 & 0.0001 \\
\hline
\end{tabular}

Table IV. If you were to engage in sexual intercourse with a partner you do not know well, a so-called 'at risk situation', would you use condoms?

\begin{tabular}{lcc}
\hline & $\begin{array}{c}\text { Girls } \\
N=332 \\
(\%)\end{array}$ \\
\hline Without any problem & $\begin{array}{c}\text { Boys } \\
(\%)\end{array}$ & 562 \\
With some difficulty & 55.9 & 19.3 \\
I would not dare to discuss the problem & 1.3 & 13.6 \\
I would rather not have sexual intercourse & 2.0 & 2.2 \\
I would not use a condom & 2.0 & 1.6 \\
I do not feel the question applies to me & 16.9 & 2.2 \\
& & 28.8 \\
\hline
\end{tabular}


perception of condom use (either because it would be embarrassing or might reduce sensation).

\section{Sexual behavior}

As shown in Table V, 69\% of the sample were sexually active; more boys than girls said they engaged in sexual relations but more girls than boys had sex on a regular basis $(P<0.001)$. Of these youngsters, $27 \%$ had had only one partner, $42 \%$ had had two to four partners and $30 \%$ more than four partners. Boys say they had had significantly more partners than girls $(P<0.001)$.

Among the adolescents who reported they were sexually active, $70 \%$ of boys (but only $20 \%$ of girls) claimed to have already bought condoms at least once. Of the sexually active adolescents, 73\% claimed to have used a condom at least once $(76 \%$ of boys, $59 \%$ of girls) but only $23 \%$ of boys and $10 \%$ of girls used condoms regularly. All of these differences between boys and girls were statistically significant $(P<0.001)$. This difference is, however, difficult to interpret, since some girls may have misjudged the question and may have answered no because only their partner used the condom!

Because adolescents who engage in sexual relations with more than one partner are obviously at a higher risk of getting STDs and AIDS, we compared attitudes towards condom use and behavior among sexually active respondents with, respectively, one partner, two to four partners and more than four partners. Regarding attitudes, there were essentially no differences between the three groups except that the respondents with two to four partners had bought more condoms than those in the two other groups.
We found no difference between the three groups regarding behavior: in other words, even in the group with more than four partners, the use of condoms on a regular basis was still low (15\%).

Among sexually-active adolescents, $32 \%$ of boys and $52 \%$ of girls reported use of the pill as a regular method of contraception; 10\% used coitus interruptus!

A regression analysis was performed to detect the influence of the exhibition on condom use, checking the age, sex, sexual activity, knowledge and the theoretical acceptance of condoms. As can be seen from Table VI, boys are significantly more likely to have handled, purchased and used condoms than girls. This was also the case for older adolescents. Quite naturally, the fact of being sexually active positively influences attitudes and behavior in respect of condom use. However, degree of knowledge does not appear to influence use.

\section{Discussion}

The results can be summarized and interpreted as follows:

(1) The level of knowledge regarding the transmission and the prevention of AIDS is high to very high. There is no difference between boys and girls or sexually active and inactive adolescents; there is no statistically significant difference between the experimental and control group either.

(2) Of the sexually active adolescents $73 \%$ claim to have used a condom at least once $(76 \%$ of

Table V. Sexual behavior of the respondents

\begin{tabular}{|c|c|c|}
\hline & $\begin{array}{c}\text { Boys } \\
\begin{array}{c}N=862 \\
(\%)\end{array}\end{array}$ & $\begin{array}{c}\text { Girls } \\
N=332 \\
\left(\varnothing_{0}\right)\end{array}$ \\
\hline Have never had sexual intercourse & 24.2 & 33.9 \\
\hline Am not having sexual intercourse at the present time & 13.7 & 12.3 \\
\hline Have casual sexual intercourse & 37.2 & 14.5 \\
\hline Have regular sexual intercourse & 24.9 & 39.4 \\
\hline \multicolumn{3}{|l|}{ For those sexually active: } \\
\hline Have had one partner only & 37.3 & 72.1 \\
\hline Have had two to four partners & 41.3 & 15.3 \\
\hline Have had more partuers & 19.6 & 12.6 \\
\hline
\end{tabular}


Table VI. Impact of the exhibition on attitudes and behavior towards condoms

\begin{tabular}{|c|c|c|c|c|c|c|}
\hline & \multicolumn{6}{|c|}{ Regression analysis: beta values } \\
\hline & sex & age & knowledge & $\begin{array}{l}\text { sexual } \\
\text { activity }\end{array}$ & group & $R$-square \\
\hline $\begin{array}{l}\text { Have you ever handled } \\
\text { condoms? }\end{array}$ & $0.24 * * *$ & 0.06 & $0.12 * * *$ & $0.26^{* * *}$ & $0.09 * * *$ & 0.16 \\
\hline Have you ever discussed & & & & & & \\
\hline $\begin{array}{l}\text { condom use with partner? } \\
\text { Have you ever purchased }\end{array}$ & 0.03 & 0.01 & 0.02 & $0.48^{* * *}$ & 0.01 & 0.23 \\
\hline condoms? & $0.38 * * *$ & 0.02 & 0.04 & $0.33^{* * *}$ & 0.00 & 0.26 \\
\hline $\begin{array}{l}\text { Do you have condoms } \\
\text { with you just in case? }\end{array}$ & $0.29 * * *$ & $0.10^{* * *}$ & 0.03 & $0.15 * * *$ & $0.09 * * *$ & 0.13 \\
\hline $\begin{array}{l}\text { Have you ever used } \\
\text { condoms? }\end{array}$ & $0.18 * * *$ & 0.01 & 0.04 & $0.56 * * *$ & 0.01 & 0.34 \\
\hline $\begin{array}{l}\text { Do you use condoms } \\
\text { regularly? }\end{array}$ & $0.14 * * *$ & $0.10 * * *$ & 0.03 & $0.27^{* * * *}$ & 0.01 & 0.08 \\
\hline
\end{tabular}

***t-test $P<0.01$

boys and $59 \%$ of girls), and $23 \%$ of boys and $10 \%$ of girls do use condoms regularly.

(3) There is no difference between the two groups in terms of condom use; however, more adolescents in the experimental group have handled condoms and have some with them 'just in case ...'.

Some methodological points deserve special mention. First, as in any survey by questionnaire dealing with topics like adolescent sexual attitudes and behavior, one cannot be sure that the results accurately reflect reality. A good explanation of the aim of the study before filling out the questionnaire and the strict guarantee of anonymity may have improved the quality of the answers. The very low rate of non-response reinforces this assertion. The comparisons between different questions dealing with the same topic (i.e. condom use) also reveal similar rates.

Secondly, during the 3 month period that elapsed from the exhibition to the evaluation, the Swiss national 'STOP AIDS' prevention campaign was initiated (February 1987) and was presented by all the media. In other words, the experimental group as well as the control group were submitted to many sources of information: this external influence should be kept in mind and explains, in our opinion, the lack of more statistically significant differences between the two groups, both in terms of knowledge and behavior.

However, it is this federal campaign which probably explains the high level of knowledge in the population surveyed: indeed, Swiss teenagers' knowledge of AIDS and STDs is quite good compared with the results of similar surveys held in the US. For instance, Strunin and Hingstron (1987), in a survey of Massachusetts adolescents' knowledge regarding AIDS, found error rates as high as $57 \%$ (e.g. getting AIDS through kissing) and most accurate answer rates fell below $60 \%$. DiClemente et al. (1986), in a survey among adolescents in San Francisco, also found a substantial percentage of wrong answers: $14 \%$ of respondents did not believe that using a condom during sex could reduce the risk of getting AIDSs, $10 \%$ of them imagined you could get AIDS by shaking hands with someone infected and about $40 \%$ thought that you could get AIDS through kissing (compared with $5 \%$ in our study). These percentages were even worse in certain subgroups (DiClemente et al., 1988) in a survey of inner-city New York adolescents, Goodman and Cohall (1989) also obtained rates that are considerably below ours. A recent survey carried out in Massachusetts has shown more comparable results with percentages of false answers ranging from $1 \%$ to $25 \%$ (Hingson et al., 1988).

Most existing surveys deal essentially with 
knowledge and attitudes, and few of them deal with rates of condom use. Considering that, in our study, more than $50 \%$ of sexually active adolescents have used condoms at least once, and also that 15-20\% use them regularly, our results are not discouraging-since Strunin and Hingson (1987) report a rate of only $10 \%$. A survey undertaken in Somerset by Bowie and Ford (1989) among 16-21 year old youngsters shows even better results, with $73 \%$ of boys and $75 \%$ of girls who were sexually active having already used condoms, and $36 \%$ of both boys and girls having used them the last time they had sexual intercourse.

The fact that the exhibition probably persuaded adolescents to handle and have condoms with them 'just in case ...' is also satisfying, since this change in behavior should increase the tendency to use condoms when needed.

However, compared with the high level of knowledge, one can be dissappointed by the remaining low rate of condom use, especially if this percentage is, as we have observed, the same whether adolescents have one or multiple partners! This result is corroborated with those of Bowie and Ford (1989). Thus, there is still, as in many other instances, a large gap between knowledge and behavior: it is in fact frequently very difficult for adolescents who engage in sexual relations, often with inexperience, embarrassment and shyness, to share with their partner the kind of discussion necessary for the effective use of condoms.

In other words, as other authors have noted (Becker and Joseph, 1988; Kegeles et al., 1988), what is badly needed in the future are prevention programs that do not focus primarily on information, but include practical counseling on topics such as sharing, trust, discussing contraception issues with partners, and purchasing and using condoms on the right occasion and in an appropriate way. This practical counseling can take many forms (Michaud et al., 1988): as in our program, it may be run by school health nurses or physicians. It may be part of sex education courses or it could be set up in different ways: through computer-based interactive programs, telephone hot-lines, encounter and selfhelp groups or, finally, by specially-trained youngsters (or 'mediators').

\section{Acknowledgements}

We should like to thank J.Martin and C.La Vecchia, who reviewed the paper and made useful comments. Mr T.Spencer kindly revised the English version of the manuscript. J.Resplandino and P.Lehmann participated in the preparation of the exhibition and of the questionnaire. Finally, the exhibition could not have been set up without the help of all the nurses who work in the 'Youth and Health Program', the cooperation of the Principal and the teachers at the 'Ecole Professionnelle de la SIC', and the assistance of partners at the 'Centre Medico-social Pro Familia' in Lausanne. Supported by a grant from the Swiss Federal Office of Public Health, Bern, and the Cantonal Public Health Service, Lausanne, Switzerland.

\section{References}

Becker,M.H. and Joseph,J.G. (1988) AIDS and behavioral change to reduce risk: A review. American Joumal of Public Healsh. 78, 394-410.

Bowie, N. and Ford,N. (1989) Sexual behavior of young people and the risk of HIV infection. Joumal of Epidemiology and Community Health, 43, 61-65.

DiClemente,R.J., Zom,J. and Temoshok,L. (1986) Adolescent and AIDS: a survey of knowledge, attitudes and beliefs about AIDS in San Francisco. American Joumal of Public Health. 76, $1443-1445$.

DiClemente,R.J., Boyer,C.B. and Morales,E.S. (1988) Minorities and AIDS: knowledge, attitudes, and misconceptions among Black and Latino adolescents. American Joumal of Public Health, 78, 55-57.

Goodman,E. and Cohall,A.T. (1989) Acquired immunodeficiency syndrome and adolescents: knowledge, attitudes, beliefs and behavior in a New York City adolescent minority population. Pediatrics, 84, 36-42.

Hausser,D., Lehmann,P., Dubois-Arber,F. and Gutzwiller,F. (1988) Evaluation des campagnes de prévention contre le SIDA en Suisse. I. Rapport de synthèse. Cah. Rech. Doc. IUMSP No. 23, p. 96.

Hausser,D., Lehmann,P., Dubois-Arber,F. and Gutzwiller,F. (1989) Evaluation des campagnes de prevention contre le SIDA en Suisse. Il. Deuxieme rapport de synthise. Cah. Rech. Doc. IUMSP No. ?, p. 110.

Hausser, D., Lehmann, P., Dubois,F. and Gutzwiller,F. (I988) Effectiveness of the AIDS prevention canpaigns in Switzerland. In The Global Impact of AIDS. Alan R.Liss, New York, pp. 219-228.

Hingson, R., Strunin, L. and Berlin,B. (1990) Acquired immunodeficiercy syndrome: changes in knowledge and betavior among teenagers, Massactusetts Statewide Surveys, 1986 to 1988. Pediatrics, 85, 24-29.

Kegeles,S.M., Adler,N.E. and Inwin,C.E. (1988) Sexually active 
adotescents and condorns: changes over one year in knowledge, attitures and use. American Joumal of Public Health, 78, 460-461.

Martin,J. and Michaud,P.-A. (1988) AIDS education in Switzerland: implementing strategies to reach groups with high risk behavior, particularly young people. Health Education Research, 3, 105-112.

Michaud,P.-A. and Martin,J. (1984) Un programme de prevention pour les apprentis et les gymnasiens vaudois. Medecine et Hygiène, 42, 437-442.

Michaud,P.-A., Resplendino,J., Palasthy,E. and Chapuisod,B. (1987) Une exposition sur les maladies sexuellement transmissibles et le SIDA pour les apprentis vaudois. Social and Preventive Medicine, 32, 210-211.
Michaur,P.A., Stutz,T. and Samuel,M. (1988) La prevention du SIDA aupres des jeunes. Sacial and Preventive Medicine, 33, $319-325$.

Strunin,L. and Hingston,R. (1987) Acquired immunodeficiency syndrome and adolescents: knowledge, beliefs, attitudes, and behavior. Pediatrics, 79, 825-828.

Office Fúdéral de la Santé Publique (1988) Un test pour la societte. Bulletin de l'Office Fedéral de la Santé Publique, 30, 399-400.

Office Federal de la Sante Publique (1990) Aids information. Bulletin de l'Office Fédéral de la Santé Publique, 3, 24-25.

Received November 16, 1989; accepted on September 24, 1990 